\title{
Els relats humorístics d'arrel lingüística: consideracions a propòsit del tipus ATU 1699 («Malentesos entre parlants de diferents llengües»)
}

\author{
Joan Borja i Sanz \\ Universitat d'Alacant \\ joan.borja@ua.es
}

\section{RESUM}

Si bé es mira, al darrere d'una rialla o d'un somriure hi ha sempre una tragèdia. Fet i fet, l'humor pren base en el fracàs i constitueix, precisament, una estratègia - privativa de l'espècie humana- per a la superació o la sublimació de les inclemències vitals. Així doncs, inventem i contem acudits que delaten la feblesa de les institucions polítiques i religioses que, suposadament, ens haurien de dignificar socialment; ens riem de la vulnerabilitat del cos humà; fem burles dels elements que ens recorden la condició zoològica, biològica i mortal (pensem només en l'inesgotable filó dels relats escatològics i sexuals; en les gràcies que desperten els gestos antropomòrfics d'un animal; en l'humor negre vinculat a la mort, les seues circumstàncies, els seus rituals; en el riure instintiu davant l'accident enregistrat per un videoaficionat; etc.

També les llengües, naturalment, són una font de rialles i calamitats: quan el llenguatge trontolla - allà on les paraules fracassen- no solament queda en evidència la presumpta dignitat de l'espècie, sinó també una dramàtica limitació en les formes de la comunicació, i en les possibilitats de concepció del món. En últim terme, el fracàs del llenguatge és el fracàs de l'ànima humana -nua, òrfena, aïllada, terriblement sola davant les complexitats de l'existència.

En aquest article ens proposem aportar algunes consideracions analítiques sobre els fonaments humoristics subjacents a diferents relats populars que tradicionalment han estat catalogats en el tipus ATU I699 (Malentesos entre parlants de diferents llengües), amb la intenció d'encetar una reflexió sobre l'oportunitat de distingir-hi uns subtipus determinats.

PARAUles CLAU

humor, etnopoètica, contarelles de riure, malentesos, ATU I699 


\begin{abstract}
If we care to look behind a laugh or smile there is always a tragedy. In fact, humour is based in failure and is a strategy particular to humans for overcoming or sublimating life's inclemencies. Thus we invent and tell jokes that betray the weakness of political and religious institutions that are supposed to confer us a certain social dignity; we laugh at the vulnerability of the human body, we make fun of things that remind us that we are after all just animals, and mortal ones at that. Indeed, we only have to think of the inexhaustible mine of scatological and sexual stories, of the amusing things that bring out anthropomorphic gestures in animals, of the black humour surrounding the circumstances and rituals of death, of the instinctive laughter caused by watching an accident that has been caught on video camera, etc.

Naturally, languages are also a source of laughter and calamities; when language stumbles, that is, when words fail, it not only draws attention to the presumptuous dignity of humans, but also highlights the dramatic limitations that restrict the way we communicate and perceive the world. In the final analysis, the failure of language is the failure of the human soul, naked, orphaned, isolated and terribly alone in the face of the complexities of existence.

In this paper we offer some analytical reflections regarding the underlying humour in different popular stories that have traditionally been catalogued as type ATU I699 (Misunderstanding Because of Ignorance of a Foreign Language) to see if we can distinguish certain subtypes among them.
\end{abstract}

\title{
KEYWORDS
}

humour, ethnopoetics, jokes, misunderstanding, ATU I699 
SEGONS UNA CÈlebre FRASE ATRIBUÏDA A MARK TWAIN, «el problema amb l'humor és que ningú no se'l pren seriosament». La pensada — ja s'entén— reivindica l'interés d'una sòbria atenció a la complexitat dels mecanismes, els orígens, els motius, els efectes i les formes de l'humor. Durant el segle xx, tanmateix, sembla que s'ha anat consolidant una sucosa tradició de teoritzacions al voltant del fenomen de l'humor. I és en aquesta tradició, dins l'àmbit cultural català, on sembla que podríem inscriure una extensa entrada que l'assagista valencià Joan Fuster dedicava, en el seu Diari, a reflexionar sobre el riure com a facultat privativa de la condició humana. El lluminós Rabelais ja ho observava en el Gargantua: «És propi de l'home riure». I I Fuster, a partir de tal sentència, enceta, amb data de l'II d febrer de I954, unes divagacions pròpies en què matisa: «L'home riu, es riu, i la més elemental observació demostra que sempre es riu de si mateix. Heus ací un aspecte de la personalitat humana francament torbador i incorregible». ${ }^{2}$

Les reflexions del Diari de Joan Fuster que parteixen d'aquesta observació ens semblen del tot pertinents per a les nostres consideracions a propòsit dels relats humorístics d'arrel lingüística (en general) i de les narracions que tradicionalment s'han catalogat dins del tipus ATU I699, «Malentesos entre parlants de diferents llengües» (en particular). I ens ho semblen, pertinents, per tal com permeten contextualitzar — ni que siga intuïtivament - els malentesos i els equívocs lingüístics com una poderosa font de comicitat $i$, en conseqüència, el lloc comú de no pocs relats populars amb intenció humorística.

Per a Fuster el riure pot tindre l'origen en la ridiculització de les coses respectades i elevades, o bé de la mateixa figura de l'home i la seua suposada dignitat:

L'anàlisi de casos risibles ens autoritza a establir-hi una distinció inicial. D'una banda, n'hi ha uns en els quals l'home es riu —es burla- de les coses que respecta: de les coses elevades, valuoses d'acord amb els criteris que regeixen el seu grup social. De l'altra, n'hi ha uns altres en els quals l'objecte del riure, de la burla, és la mateixa figura de l'home, en la seva intrínseca dignitat. Per a totes dues hipòtesis, és essencial que existeixi, en aquell qui hi riu, el reconeixement previ d'una participació seva, volun-

I. En el mateix Diari (1952-1960), Fuster publica, precisament, un llarguíssim poema en homenatge a Rabelais on cita allò del Gargantua: «pour ce que rire est le propre de l'homme» (I969: 68); i on també podem llegir: «L'home, ¿què és, / en última instància? Una fisiologia que riu, / si se'm tolera la fórmula» (Fuster 1969: 69).

2. Entre tants altres teòrics de l'humor, en la mateixa direcció que Fuster, també A. Pereda (1983), reivindica —ell des de premisses psicoanalítiques- el caràcter substancial i privatiu que el riure (i el fet de riure's de si mateix) té per a l'espècie humana: «el hombre es el único ser que puede burlarse (cuestionando), su cultura, sus hábitos, sus formas sociales, sus sistemas políticos, sus costumbres, pero sobre todo, y lo más importante, es el único que puede reírse de sí mismo. Y no es poco lo que eso aporta a su salud psíquica». 
tària o involuntària, en l'òrbita estimativa de què fa burla (Fuster I969: II7-II8).

En un cas i l'altre, ben mirat, al darrere del riure hi ha sempre una tragèdia: la sublimació en forma de rialla davant l'evidència que la condició humana és fatalment vulnerable. Adesiara les circumstàncies de la vida palesen que, a pesar de totes les ínfules de grandesa, els homes - i les dones- no són sinó animals fràgils, mortals, sotmesos a les inclemències del temps, el cos, l'atzar i una enorme quantitat d'imponderables fisicoquímics:

L'home es forja un alt concepte d'ell mateix, s'autosublima — sembla que sempre ha tingut aquesta tendència. Quan, per alguna circumstància, es veu grotesc, desposseït d'aqueixa aurèola emfàtica, en comptes de lamentar-se'n, un instint immediat, irreprimible, el duu a burlar-se'n. I no es burla aleshores d'altra cosa sinó del seu fracàs, de la fallida que hi experimenta la imatge digna. S'hi podria parlar d'una veritable complaença en la degradació. I, en el fons, allò que es degrada en el ridícul de qualsevol individu és l'espècie humana sencera, la nostra orgullosa posició (Fuster I969: I2O).

Sobre la base d'aquests plantejaments, Fuster revisa quins són els motors del riure. I hi distingeix així la burla relativa a referents socials que són considerats valuosos i importants; ${ }^{3}$ la corresponent a la pornografia i la família; ${ }^{4}$ la de l'home accidentat - el que cau pel carrer, posem per cas_-; la que es deriva de la lletgesa extraordinària d'una cara; la d'una persona fora de si; ${ }^{5}$ el gest antropomòrfic d'un animal;' l'insult personal; les pors, les reserves i les animadversions davant

3. Escriu Fuster: «Exemples claríssims [...] són els acudits contra les institucions polítiques i religioses i els seus representants» (I968: II8); «Les arts, la medicina, i l'administració de justícia hi són també matèria predilecta, donada la seva òbvia "respectabilitat" (I968: I20).

4. En aquest sentit, Fuster parla de «dues maneres ben esteses del nostre riure: l'acudit pornogràfic i l'acudit diguem-ne antifamiliar» (I969: II9). Quant a la primera, hi afig: «L'acudit pornogràfic suposa una ofensa lateral als principis ètics, i existeix, precisament, en funció d'aquests principis. Com més estricta sigui la moral dominant d'una societat, més es "tancarà l'ullet" en tocar els temes del sexe, i més alliberadora semblarà la transgressió verbal del tabú» (Fuster 1969: II9). Pel que fa a la segona (on hi ha el motiu de la sogra, de l'home resignat, del parentiu carnal, de la vida vulgar, etc.), reflexiona: «L'home frueix representant-se les conseqüències infelices d'una institució que està destinada a promoure la seva felicitat. En la família concorren, a més a més, prestigis polítics — jurídics_- i religiosos; hi ha, sobretot, el sentiment naturalíssim del parentiu carnal. El caràcter sagrat d'aquestes diverses pressions es lliga per contrast picant, a incomoditats i vexacions inevitables. La vida vulgar del matrimoni és un tema fecund i preferit per a provocar el riure, la burla» (I969: II9-I2O). Sobre la teorització de l'humor derivat de la sexualitat, no pot deixar de citar-se el cèlebre treball de Freud Der Witz und seine Beziehung zum Unbewußten (1905), ni que siga per l'exotisme d'algunes de les idees que s'hi exposen: «La comicidad de lo sexual y de lo obsceno merecería un examen más detenido que el que aquí podemos dedicarle y cuyo punto de partida sería de nuevo el desnudamiento. Un desnudamiento casual nos produce un efecto cómico porque comparamos la facilidad con que gozamos del espectáculo de la desnudez con el gran gasto [sic] que hubiera sido necesario para conseguir por otro camino el mismo fin» (Freud 1905: 127).

5. En aquest supòsit, Fuster considera «el boig, l'idiota, l'irritat». I hi anota: «Observem que la burla, en aquestes situacions, es limita a afectar la dignitat aparatosa i autoatribuïda» (I969: I20).

6. L'assagista valencià, en aquest punt, no s'està d'apreciar que «també les burles pornogràfiques s'expliquen des d'aquest cantó: en elles, l'home resta abandonat als seus ressorts 
d'altres comunitats culturals diferents a la nostra; i també la comicitat que té a veure amb l'absurd i la falsa lògica de les paraules. ${ }^{8}$ Doncs bé: és precisament en relació amb aquesta última qüestió (la de l'absurd i la falsa lògica de les paraules) que considerem que potser resulta oportú i productiu conceptualitzar, analitzar i entendre les formes de l'humor derivades dels malentesos lingüístics.

La jocositat escatològica o sexual, analitzada amb un mínim distanciament, resulta ser un mecanisme de defensa davant la indefugible animalitat d'una fisiologia que imposa a la racionalitat humana els seus instints primaris i l'eventualitat (o la certesa!) de la degradació física; l'humor macabre i l'humor negre prenen base en la desgràcia inevitable de la mort, la vellesa o la fragilitat despòtica del cos; i, igualment, els somriures i les rialles que emanen dels equívocs i els malentesos lingüístics no són sinó una natural reacció, paral·lela a les anteriors, per a l'abismal solitud i orfandat a què ens condemna la limitació o la fallida del llenguatge. Si les paraules són les que ens permeten comunicar-nos, i també aprendre i aprehendre el món, cada volta que fallen ens recorden la tràgica i rotunda solitud de l'individu, absolutament perdut en un univers estrany i incomprensible. Cada volta que falla el llenguatge es fa palesa la pròpia condició de nàufrags en el mar de la vida; la insalvable impotència per a entendre els altres, per a fer-nos entendre nosaltres mateixos $i$, en fi, per a entendre el món: queda en evidència - com apuntàvem adés- la fatal vulnerabilitat de la condició humana. I riem: riem com a complexa, desenvolupada i madura forma de sublimació, de superació, de destranscendentalització. Riem del que ens fa mal; del que ens delata fràgils, volubles, intranscendents, impotents, fracassats. Efectivament, «rire est le propre de l'homme». L'home és home(i la dona, dona) gràcies al llenguatge: a la nostra ànima - per dir-ho així- feta de paraules. I quan les paraules fallen, sentim cedir la primíssima corda al precipici sobre el qual fa equilibris l'existència. I hi reaccionem amb el vell antídot que serveix per a exorcitzar pors, absurds, frustracions, desesperances, angoixes, sense sentits. Riem. Amb riallades escandaloses o somriures subtils, segons qui i segons el cas. Riem. Ben mirat, aquesta és la base sobre la qual es construeixen els relats humorístics d'arrel lingüística. I així sembla que ho intuia Joan Fuster quan apuntava:

La lògica, i les convencions del llenguatge —que en són el suport, en les relacions corrents-, reben un escarni deliberat, justament per ser una part essencial d'aquella condició superior, digna, de l'home (Fuster I969: I22).

En realitat —aquest és el punt on volíem arribar-, aquesta suposada «condició superior, digna, de l'home» queda malmesa cada volta que trontolla el llenguatge. I per això els malentesos lingüístics, del tipus que siguen (un malentés és sempre un fracàs de les paraules, l'evidència de les seues limitacions), són una

zoològics, és un simple ninot excitat que, vist en fred, resulta irrisori» (I969: I2I).

7. Sense embuts, hi especifica: «els antagonismes nacionals —o més clarament: la xenofòbia» (I969: I22).

8. Com a exemples, Fuster hi apunta: "Era un senyor tan alt, tan alt, que per a posar-se el capell necessitava pujar dalt d'una cadira." "Diu una senyora a un senyor que passa pel seu costat: 'Caram, En Tal, que canviat que us trobo!' Contesta ell: ‘Però si jo no sóc En Tal!' I ella: 'Més a favor meu encara!'”» I hi conclou: «En un cas i en l'altre, ens riem de la falsa lògica de les paraules, impecable en la seva trajectòria però absurda en la conclusió» (I969: I2I-I22). 
font recurrent per a l'humor popular. El tipus ATU I699, de caràcter miscel-lànic, que l'índex internacional Aarne-Thompson-Uther (Uther 2004) situa en l'apartat de «Rondalles i contarelles de riure» (entre el I200 i el I999), permet classificar, precisament, els relats humorístics d'arrel lingüística en què es recrea el motiu concret dels malentesos, atenent —això sí- el cas particular de les confusions i les corresponents situacions còmiques que es produeixen entre parlants de llengües diferents:

I699 Misunderstanding Because of Ignorance of a Foreign Language (including the previous Type I699A). Miscellaneous type. Two people who speak different languages cannot understand each other. One of them pronounces the words so that they seem to have a different meaning, or the words sound like different words in the other person's language. Often an absurd conversation leads to unexpected events.

In some variants the misunderstanding happens because one person does not understand a foreign word (technical term). Or an ambiguous message (statement) leads to the discovery of a criminal (planned crime).

Dins l'àmbit cultural català, el modèlic catàleg de Carme Oriol i Josep Maria Pujol adapta el descriptor d'aquest tipus I699 de la manera següent:

I699 «Malentesos entre parlants de diferents llengües»

Dos personatges que parlen llengües diferents es troben. Un d'ells intenta parlar en la llengua de l'altre i utilitza paraules que són homòfones amb les de l'altra llengua però que tenen significats que no corresponen als de la pròpia. Aquesta situació dóna lloc a malentesos i situacions còmiques. (Oriol-Pujol 2003: 338)

Oriol i Pujol, fet i fet, hi cataloguen set dels 5.759 relats populars que han estat documentats i processats per a nodrir l'admirable base de dades RondCat. Aquests set relats constitueixen un corpus concret i abastable que estimem interessant per a encetar i il-lustrar algunes reflexions i consideracions potser rellevants en relació amb l'anàlisi i la catalogació de relats humorístics d'arrel lingüística. Atenent-ne a més la brevetat, val la pena reproduir-los ací, un a un, íntegrament o en la part essencial, per a habilitar els comentaris subsegüents. El primer, de títol «A servir a Saragossa», va ser publicat en el volum d'Artur Quintana Lo Molinar: literatura popular catalana del Matarranya i Mequinensa, i explota l'efecte humorístic d'un malentés produït per l'homofonia entre el substantiu espanyol cama ('moble per a dormir') i el mot català cama ('extremitat inferior'):

\section{[I]}

Una volta va anar una noia, una noia jove, a servir a Saragossa. I claro, pués poca pràctica en lo llenguatge, perqué ací es parle el català i allí el castellà. Pués, la pobra noia no entenie bé. I va arribar allí. Va cenar, que va pujar amb lo correu, i a l'undemà, pués ja la duenya li va començar a donar faena i li va dir:

-Mira, primero que nada, ahora sácame las camas al balcón.

Qué fa ella? S'assente al balcó amb les cames penjant. I, claro, al cap d'una hora o així, la duenya puge: 
—Pues ¿no te he dicho que sacaras las camas en el balcón?

I diu:

-Pues ya las tengo.

Allí estave amb les cames penjades al balcó i volie estar tot lo dia, saps? Ja són casos!

En el segon, «Lo pont del mesquí» (del mateix volum de Quintana), la confusió còmica és generada per l'homonímia entre el quantitatiu dialectal de la Codonyera pont ('gens') i el substantiu del català general pont ('construcció per a salvar una depressió o creuar un obstacle'):

[2]

Que anave un sinyor, a la Codonyera, amb un carro i unes mules per la carretera i a l'arribar el pont del riu, pués allavons li diu:

—Que passe molta aigua?

I l'altre diu:

-No en passe pónt.

I l'altre diu:

Ah, pues, si no passe pont, me m'entorno, perqué si no hi ha pont...

I se'n va entornar cap a casa (Quintana I995: I98). ${ }^{9}$

També recopilats per Artur Quintana, però del recull Bllat colrat! Literatura popular catalana del Baix Cinca, la Llitera i la Ribagorça, són els tres relats següents. En el primer d'aquests tres nous acudits, «A Colls parlen castellà», el malentés es produeix per l'homonímia entre el topònim Colls i el plural del substantiu coll ('part que uneix el cap amb el tronc'), que propicia una traducció impertinent i irrisòria del topònim:

[3]

Una de Colls va anar a la festa major. I la va fer ballar un maestro. I, claro, com que era el maestro, ella, pues enraonava castellà:

- ¿De Dónde eres?

-De Cuellos (Quintana 1997: 20I-202).

El segon (el quart dels set indexats en total), «Els de Montfalcó parlen castellà» recrea la divertida confusió que es produeix quan un personatge de Montfalcó, intentant parlar castellà, tradueix equivocadament cap ('part superior del cos humà') per *cabo (en comptes de cabeza), forma que resulta homònima —amb el corresponent malentés- a la del substantiu cabo ('militar de rang immediatament superior al del soldat'): ${ }^{\text {Io }}$

9. Al final del relat, el recopilador afig aquesta nota aclaridora: «R. Es diu de la gent de la Codonyera, que fan servir el mot 'pónt' per al mot que a Ràfels, i en general al Matarranya, es diu 'gens'».

Io. Aquesta mateixa confusió entre *cabo ('cap') i cabo ('militar entre soldat i sergent') és el motor humorístic del relat «La padrina que no sabia castellà»: «I també abans, quan hi eren eixes abueles, que van vinre els soldats, i no sabiven re de castellà, re, re, re. I un dia ploveva molt. I puiava un soldat pel camí i natres pititetes. I diu: / —Se mullará el cabo. / Li voleva dir que se banyaria el cap. I el soldat diu: / -Si llueve mucho, hasta el sargento (Quintana I997: 
[4]

Diu que n'hi havia un paio a Montfalcó i que estaven arrancant trumfes i diu que eren molt gordes. I els va aturar la guàrdia civil. I li voleven dir que eren tan gordes com el cap i no sabeva castellà. I no ho sabeva dir. I diu que anava el cabo de la guàrdia civil i diu:

-Sí, sí, gordas com al cabo.

I li contesta:

—Com a jo? (Quintana I997: 204).

«El porquer», tercer dels relats de Quintana (I997) i cinqué del corpus d'Oriol i Pujol, recrea la situació còmica que s'origina per la confusió entre la forma interrogativa castellana por qué i la concreció fonètica, en català oriental, del substantiu porque[r] ('pastor de porcs'):

[5]

Un xicot de l'Estall va anar - Hera [sic] guardat sempre porcs. I quan se'n va anar al servici, pués li van preguntar, diu:

- ¿Y usted qué hacía en su casa?

Diu:-Porque(r).

I no el van sacar d'astí (Quintana I997: 204). ${ }^{\text {II }}$

El sisé dels relats, «El captaire foraster», és una breu narració recopilada per Josep Bataller (200I: 53): el malentés que hi desferma l'efecte humorístic s'origina per la semblança — quasi coincidència-, per fonètica sintàctica, entre l'expressió castellana «roto va» ('trencat va') i el topònim Ròtova (el municipi de la Safor on va ser recollit el motiu):

[6]

Això era una vegada, quan es va acabar la guerra, que un home foraster anava captant. Arriba a Ròtova i pregunta a un com es deia el poble.

-Ròtova — li va respondre.

I aquell va comentar:

— «Bastante roto voy yo.»

Continua caminant i, en aplegar a Almiserà, pregunta també pel nom de la població.

-Almiserat - li diuen.

20I). Tot i que el RondCat fitxa però no cataloga aquest relat, entenem que és del tot anàleg a «Els de Montfalcó parlen castellà» i que, per tant, es podria també adscriure al tipus i699.

II. Tot i que la versió de Quintana no ho recull, s'entén que l'interlocutor castellà, davant aquella resposta («porque[r]»), deu entendre «ipor qué?», amb la qual cosa la conversa absurda que s'hi intueix podria continuar, per exemple: «Cómo que «por qué»? Dígame: ¿qué hacía usted en su casa?»; «Porque[r]»; «Me toma usted el pelo? «Por qué»? ¡Porque se lo pregunto yo! ¿qué hacía usted en su casa?». Etc. És en aquest sentit que l'informant narra: «I no el van sacar d'astí». 
I ell fa:

—«Bastante miseria tengo yo» (Bataller 200I: 53).

Per fi, el seté, «A servir a Saragossa», no és sinó una nova versió, arreplegada a Massalió per Pasqual Vidal i Fígols (2005) - amb el mateix títol i tot-, del relat que Quintana (I995) havia recollit a Nonasp:

[7]

Una volta va anar una xica jove de Massalió a servir a Saragossa [...]

Així li van manar:

-Mira, hoy me sacarás las camas al balcón para que se aireen.

En escoltar-ho, la xica va dir-se entre ella:

—Quines coses més rares tenen eixa gent; mira que dir-me que posa les cames al balcó perquè els toco l'aire, com si no me les rentara. Però ja que m'ho han manat, ho hauré de fer. Va i s'asseu al balcó amb les cames penjant.

Al cap d'una mica, la mestressa la veu allí asseguda al balcó i, tota enfadada, la renega dient-li:

-No te pagamos para que te sientes al balcón sin hacer nada. ¿No te he dicho que sacases las camas al balcón?

La xica de Massalió, tota empudegada, li contestà:

-Cony, ¿pues no ve que ya las tengo?

$\mathrm{Ai}$, quines coses passaven per tindre de parlar una llengua que no era la nostra! (Vidal i Figols 2005: 95).

A les set narracions que el catàleg d'Oriol i Pujol etiqueten com a ATU I699, en podem afegir una vuitena, dins del domini lingüístic del català, si consideràvem l'excel-lent treball de Rafael Beltran Rondalles populars valencianes. Antologia, catàleg i estudi dins la tradició del folklore universal: Beltran hi cataloga també el relat «Joanet, el dels pinyols», ${ }^{\text {I2 }}$ de Joaquim González Caturla, en què la clau humorística (com en els contes «Els de Montfalcó parlen castellà» $\mathbf{i}$ «A Colls parlen castellà») rau en la traducció macarrònica i impertinent no ara d'un topònim sinó d'un antropònim. «Joanet el dels pinyols» passa a ser, en la llengua castellana que el protagonista no domina, «Juega limpio» (traducció de Joanet, forma confosa amb la pronúncia dialectal ju[g]a net) «de los piñuelos»:

[8]

-Em diuen Joanet el dels pinyols [...].

-Muchacho, habla en cristiano y dime cómo te llamas.

Llavors, Joanet, tot fent un gran esforç, li ho va aclarir:

—Em diuen Juega limpio el de los piñuelos (González 2005: I24-I25).

Sembla evident, en qualsevol cas, que els relats humorístics d'aquesta sèrie presenten una clara relació amb uns altres tipus ATU com el I698 (Deaf Persons

I2. Tot i que el projecte Rondcat documenta i fitxa aquest relat, no l'adscriu a cap tipus ATU concret. 
and Their Foolish Answers), el I698G (Misunderstood Words Lead to Comic Results), ${ }^{\mathrm{1} 3}$ el I698B (Travelers Ask the Way), el I698D (The Wedding Invitation), el I698H (The Deaf Man in the Tree), el I698I (Visiting the Sick), el I698J (The Misunderstood Greeting), el I698K (The Buyer and the Deaf Seller) i el I698M. I també amb el I322 (Words in a Foreign Language Thought to be Insults), el I322A (Grunting Pig) o el I700 (I Cannot Understand You). Al capdavall, parlem sempre de malentesos lingüístics com a font (forma o fórmula) de l'humor. Tal com suggeríem adés: de la comicitat sorgida com a sublimació pel fracàs del llenguatge, regal de comunicació —o única taula de salvació en la singlada de la vida.

Una simple consulta en la base de dades del RondCat ens permet observar que, en el cas català —que és el que inspira les nostres consideracions-, de tots aquests tipus només els I698 i I698G tenen relats efectivament documentats. El tipus I698 («Deaf Persons and Their Foolish Answers»; «El diàleg de sords», en la versió catalana $)^{\mathrm{I} 4}$ apunta, per la seua part, a un tipus concret de malentés lingüístic: el que es produeix com a conseqüència de la discapacitat auditiva dels personatges. Així, doncs, en aquesta forma de comicitat, al fracàs del llenguatge se suma també el de la disfunció orgànica. La rialla emana, per tant, d'una doble necessitat de compensació davant d'un parell d'inclemències vitals que Fuster tipifica en el seu assaig: d'una banda, la inoperància i l'absurd de les paraules — l'«escarni» de «la lògica» $\mathrm{i}$ «les convencions del llenguatge» (Fuster I969: I22)—; de l'altra, la discapacitat física que evidencia la implacable submissió de la racionalitat humana a l'eventualitat d'un accident o una insuficiència fisiològica.

Entre els «diàlegs de sords» amb efectes humorístics que Oriol i Pujol cataloguen com a ATU I698 trobem l'exemple d'aquesta conversa absurda que, amb el títol «La iaia sorda», va ser recopilada a Bolulla (la Marina Baixa) per Maribel Guardiola i Vicent Beltran (2005: 2I8):

[9]

-Uela, neva.

-Brega?

-Neu per les teulades.

-Pistolades?

-Neu a pilots.

-Hòmens morts? Tanca, tanca la porta que no mos entren dins de casa!

Es tracta d'un diàleg quasi coincident amb el que Josep Bataller (I98I: 73) havia recollit en les Contalles populars valencianes:

[IO]

-Mare, ja neva.

-Hi ha brega?

-Sí, per les teulades.

I3. Les traduccions al català que Oriol i Pujol (2003) proposen per a aquests tipus són: I698, «El diàleg de sords»; I698G, «Malentesos còmics».

I4. ATU I698, «El diàleg de sords». Una família de sords mantenen un diàleg en què les preguntes i les respostes no tenen cap relació entre elles. ATU I698 Deaf Persons and Their Foolish Answers «Miscellaneous type. Two (more) people cannot understand each other because their impaired hearing. Misunderstandings ensue». 
-A navaixades?

-Sí, a pilots.

—Cauen homes morts? Tanca la porta, fill. ${ }^{15}$

Entenem, d'altra banda, que el repertori d'exemples indexats com a ATU I698 en el RondCat encara podria perfectament ampliar-se amb el relat, més extens, «Els sords», recopilat per Ester Limorti i Artur Quintana al Carxe. Els malentesos ací van succeint-se per raó de la sordesa de tots els membres d'una família:

[II]

Una família que tots eren sords. I li diu la dona. Pel matí s'alça i diu:

-Per qué no vas a la carnisseria i te portes una poqueta car(n), que fem hui putxero, hui que és dumenge?

Arrea l'home i a mitjan camí s'encontra en uno que li devia i li diu, aquell:

-Buenos días, compadre?

—Que te pague?

Diu: -Buenos dia [sic] le ha dicho!

-Que me va a sitar a la justicia?

Ah, se va assustar i se'n va tornar corrents. I aplega a la casa i li diu a la dona, diu la dona:

-Pero, xico, que no m'has portat car(n)?

Diu: -Si m'ha encontrat en Fulà i m'ha dit que li pague. Sinós va a citar-me al jusgat.

Diu: -Bueno, tu tens valor! Per qué no haia de la cuixa, ja no n'has portat.

Se'n va i se ho diu a la filla que estava amorzant. Diu:

-Mira el pare, que valor té: l'ha enviat a la carnisseria i perqué no havia de la cuixa, no n'ha portat p'a fer la dina.

I la filla diu:

-Sí, sí, viudo o fadrí,

que li haguera dit que sí.

Se'n va la filla a on estava l'abuela amorzant tam(b)é. Diu:

-Mire, abuela, lo que ha fet mon pare: m'ha (e)ixit un nóvio i, perqué diu que era viudo, no l'ha vollgut. I jo l'ha dit que viudo o fadrí que l'haguera dit que sí.

I5. Com a curiositat, no ens estem d'apuntar que aquest exemple ens evoca la pròpia infància, i el record de l'àvia paterna, Anna Maria Pérez Súria, a qui ben sovint escoltàvem declamar, veu impostada i enriallada, una versió abreujada del mateix motiu: «-Mare, neva. / —Que hi ha brega? / —Cau a pilots. / — Hòmens morts? Tanca la porta!». Per la seua part, Guardiola i Beltran recullen en el seu volum boluller un segon dialeg de «La iaia sorda»: «Una xiqueta que parlava en sa uela que estava com una maça. I li deia: / -Uela, ha vengut la mestra. / -Ai! T'ha picat una vespa? Pobreta! / -Que no, uela, que no! Que ha vingut la mestra. / -T'ha picat una vespa» (Guardiola-Beltran 2005: 218). 
Diu: Si, filla, sí, un traguet,

que ni encara que haguera segut agret (Limorti-Quintana I998: I5I-I52). ${ }^{16}$

També al motiu dels malentesos lingüístics originats per deficiències auditives apunta el motiu ATU I698G (Misunderstood Words Lead to Comic Results) que, segons The Types of International Folktales, és un tipus miscel-lani on podrien encabir-se els relats que respongueren al descriptor següent:

Miscellaneous type. (Including the previous Types I698F and I698L.) A deaf person misunderstands similar-sounding words, which leads to unexpected (comic) results or dialog. Cf. Type I698N.

In some cases, someone feigns deafness in order to avoid an obligation or some other unpleasant situation.

En la corresponent adaptació al context cultural català, Oriol i Pujol estimen oportú obviar el detall de la sordesa del personatge - a pesar que, en realitat, és el veritable denominador comú de les variants i698- i, fent un exercici de concreció, aposten per catalogar ací un únic tipus de relat: el de «Bo seria», una narració humorística en què la comicitat s'origina per la confusió entre la forma verbal boçaria ('vomitaria') i l'expressió bo seria. ${ }^{17}$ I l'única mostra d'aquest tipus que s'hi documenta és, precisament, la narració «Bo seria» que, dins l'epígraf «Facècies lingüístiques», recullen Maribel Guardiola i Vicent Beltran a Bolulla (la Marina Baixa):

[I2]

Hi havia un uelet que estava molt malaltet ja, vellet. I la filla enviava el fill, el netet. Diu:

-Vés veges el uelo si vol que li duguem algo p'a menjar, perquè o si nos, es morirà l'auelet.

I se n'anava el xiquet per amunt i diu:

-Auelo, ma mare diu què vol p'a menjar. Diu que si vol fer unes carxofetes, una coseta...

I l'auelet feia: -Ai! Bo seria...

I el xiquet baixava i li deia a sa mare: -Diu que ho boçaria.

—Ah! —diu-Pos si ho ha de boçar no li fem res.

Al cap d'un rato: [...]

-Auelo, unes queradilletes aixina, un conillet de les Índies, ben cuitet, ben arregladet.

I l'auelet feia: —Ai! Bo seria.

I6 Aquest relat, documentat i fitxat bibliogràficament en la base de dades RondCat, no hi ha estat adscrit a cap tipus ATU.

I7. Fet i fet, la proposta de descripció que hi fan Oriol i Pujol, amb el títol «Malentesos còmics», és: «Un vell està malalt. El seu nét li pregunta si vol menjar alguna cosa i ell li contesta: "Bo seria". El nét entén: "ho boçaria" [ho vomitaria] i no li dóna res per menjar. El vell es mor de gana» (en la versió anglesa, "An old man is ill. His grandson asks him if he would like anything to eat and he answers, "Bo seria" [That would be nice]. The grandson thinks he has said, "Ho boçaria" [That would make me sick]. Thus, he does not give his grandfather anything to eat and the old man dies of hunger»). 
I se n'anava per avall el xiquet i diu:

-Diu que ho boçaria.

-Pos si ho ha de boçar, res.

I al cap de dos o tres dies, l'auelet va expirar per no boçar, es va mori $r$ i en pau (Guardiola-Beltran 2005: 217).

Tot i que aquesta facècia és l'únic cas indexat per Oriol i Pujol com a I698G, hi ha uns altres relats catalogats en el RondCat que hi comparteixen idèntica fórmula humorística: el malentés originat per l'homofonia que produeix la fonètica sintàctica. És el cas, sense anar més lluny, de les narracions que Oriol i Pujol agrupen en el tipus català que provisionalment designen com a C-OI7: «El noi que volia cervell». ${ }^{18}$ Es tracta d'una altra facècia lingüística, en què la coincidència de concrecions fonètiques entre cervell i ser vell genera el sabut malentés i la corresponent situació irrisòria. Aquest n'és l'aclaridor resum redactat per Oriol i Pujol:

Un vell està menjant cervell de xai. El seu nét li diu que vol «cervell». L'avi entén que vol «ser vell» i li contesta que ell voldria ser jove. Quan s'ha acabat de menjar el cervell, el nét li diu que volia cervell d'aquest que tenia al plat i l'avi li contesta que li hauria pogut dir abans. ${ }^{19}$

Dues són, en la monumental base de dades d'Oriol i Pujol, les mostres textuals que justifiquen la proposta d'encunyar aquest tipus C-oI7. I totes dues són curiosament valencianes: l'una és l'«Aplec d'acudits» fixat per Bataller (I997: I09) i l'altra, la documentada pels mateixos Guardiola i Beltran, també a Bolulla:

[I3]

Un uelo que estava menjant, estava esmorzant i tenia un cervell de borrego i anava menjant-se el cervell. I tenia un netet allí i li feia:

-Uelo, jo voldria cervellet.

I el uelo feia: -jo voldria ser jovenet.

I hala! Hala! (Guardiola-Beltran 2005: 2I7).

Tanmateix, a aquests dos casos valencians podríem afegir el que, amb el títol «Jo vull cervell», espigola Artur Quintana a Nonasp (Matarranya), amb l'únic de-

I8. Cal recordar que, tal com Oriol i Pujol expliquen en l'apartat «La catalogació de les rondalles», «En el cas de les rondalles que no tenen entrada en l'índex internacional, però que s'han publicat amb més d'una variant, hem fet servir una numeració pròpia, estrictament correlativa, precedida sempre per una "C-" que indica que aquest és un tipus documentat de moment a les terres de llengua catalana, a l'espera de saber si és un tipus internacional, conegut també en altres àrees lingüístiques» (Vegeu l'apartat «Com cataloguem les rondalles que no tenen entrada a l'índex internacional», dins la secció «La catalogació de les rondalles», en el «Contingut» del RondCat: <http://www.sre.urv.cat/rondcat/cataloguen. php?lang=cat>; data de consulta: gener de 2013).

I9. La versió anglesa del resum és: «C-oI7 The boy who wanted lamb’s brains / An old man is eating lamb's brains. His grandson says he wants some "cervell" [brains]. The grandfather thinks he is saying that he wants to "ser vell" [be old] and answer him saying that he would like to be young. When he has finished eating his grandson says to his grandfather that he wanted some of the brains the old man was just eating. The grandfather asks him why he didn't say so before» (vegeu-ne el resultat de la cerca en <http://www.sre.urv.cat/rondcat/ cercar.php?lang=eng $>$; data de consulta: gener de 20I3). 
tall diferenciador —absolutament accessori- que, en comptes de xai, iaio i nét mengen conill:

[I4]

-Iaio!

-Qué vols?

-Jo vull ce(r)vell.

I son iaio li contestave:

-I jo voldria ser jove.

Al cap d'un ratet lo cervell se l'anave minjant, l'agüelo.

-Iaio, jo vull ce(r)vell!

-I jo vull ser jove com tu, cony!

Conque en resumides, que l'agüelo se va minjar el cervell i al xiquet no li'n va donar (Quintana I995: I99).

Arribats en aquest punt, i desplegat ja un mínim corpus de relats humorístics d'arrel lingüística, sembla ja moment d'observar que la clau humorística dels relats [I3] i [I4] és idèntica a la de [I2]; i que comparteix amb totes les anteriors l'efecte còmic d'un mateix tipus de malentés verbal. Amb independència que hi entren en joc (o no) més d'una llengua (com en els casos [I], [3], [4], [5], [6], [7] i [8]), dialectes diferents (com en [2]), o personatges sords o sonats que propicien la burla (el cas de [9], [Io] i [II]), si bé es mira, què si no l'homofonia total o aparent, la incomprensió, la fallida de les paraules i la consegüent insuficiència del llenguatge origina l'efecte irrisori de totes les situacions recreades? Ben mirat, no és sempre una mateixa classe de confusió lingüística la que desperta el somriure? I en segon lloc, però no menys rellevant, té sentit abaixar al nivell de les paraules concretes d'una llengua determinada —o d'una combinació de llengües en contacte- a l'hora de fixar un criteri per a la catalogació dels relats corresponents? Altrament formulat: val la pena distingir tipus distints, en català — per exemple-, per a, d'una banda, les facècies sobre la confusió boçaria / bo seria, i, de l'altra, els malentesos derivats de cervell / ser vell? Té sentit adjudicar un codi com el C-or7 (distint del I698G) per al relat que confon les formes cervell i ser vell, sent que tal confusió només es pot produir en català i l'efecte còmic resulta consegüentment intraduïble? Quina productivitat tindria aquesta estratègia a l'hora de contrastar internacionalment els relats humorístics d'arrel lingüística? Atenent que les homonímies o les semblances entre paraules o expressions són específiques de cada sistema lingüístic — de cada idioma—, i que els relats humorístics derivats de la confusió són, per tant, també restringits a l'idioma en qüestió, com se'n poden encarar anàlisis comparatistes? Com s'hi poden valorar les eventuals analogies? Com s'hi podria salvar l'especificitat idiomàtica, en les catalogacions de l'índex internacional?

La resposta passa, potser — i acceptem ací el risc de comprometre un posicionament- per distingir tipus concrets de situacions en què es produeix el fracàs del llenguatge i, per tant, de la comunicació. És només una proposta (que exigiria, naturalment, reflexions, debats i sistematitzacions futures): a l'hora de catalogar el magma heterogeni i miscel-lànic de relats populars amb caràcter humorístic d'arrel lingüística, potser valdria la pena establir una tipologia de contextos, cir- 
cumstàncies, conjuntures i fenòmens lingüístics i comunicatius en què es produeix una —passe l'expressió- fallida del llenguatge amb conseqüències còmiques. Tal com hem vist, The Types of International Folktales distingeix amb un tipus específic (ATU i699) els «Malentesos entre parlants de diferents llengües»; i amb tota la sèrie I698 (apuntàvem adés els codis I698, I698B, I698D, I698G, I698H, I698I, I698J, I698K i I698M) alguns casos típics d'incomprensió per hipoacúsia. Però la casuística en les formes de la insolvència verbal —i, per tant, en les possibilitats de l'humor alliberador de frustracions - no s'esgota, ni de bon tros, en aquests tipus: una simple ullada al repertori popular dels acudits de base lingüística permet observar que són moltes més les possibilitats i les formes del fracàs lingüístic, els filons de l'humor, els tipus de relats humorístics amb vigència presumiblement internacional.

Vegem-ne, ni que siga com un primer pas per a reflexions, debats i sistematitzacions posteriors, alguns dels tipus de «contarelles de riure» - i els corresponents exemples-que s'hi podrien tenir en consideració:

a) Un personatge entén malament — per culpa de falsos amics o per raó del context- les paraules d'un segon personatge que parla en una llengua estrangera, i el fet crea una situació còmica:

\section{[I5] El de No compre pa!}

Quant anàvem a Alger, agarràvem el barco. I en el barco portaven sacs de farina.

I se'n veuen uno pixant; allí un home pixant. I diu: - Mira el tio cerdo! Està pixant en la farina! Ai!

I se'n va i li diu: -Escolte, vosté sap que està pixant en la farina?

Diu: -Je comprends pas.

-Vosté està pixant!

- Je comprends pas.

-No veus que no compra pa? Pues per això pixa en la farina! (MenagesMonjo 2007: 186$){ }^{20}$

\section{[I6] [El francés i el sac de la farina]}

-So marrano, què fas pixant-te damunt de la farina?

I aquell: - No comprenc pa.

-I per què no compres pa el pixes damunt de la farina? (Guardiola-Bel$\operatorname{tran} 2005: 222)$.

20. En relació amb els malentesos lingüístics entre parlants de llengües diferents (motiu que defineix l'ATU I699), tocant a la llengua catalana hem trobat un filó d'exemples il-lustratius, alternatius al del sabut conflicte lingüístic entre català i espanyol, en el cas dels nombrosos valencians que van emigrar a Algèria i que hi van entrar en contacte amb la llengua francesa (que molts desconeixien). Aquest curiós i important fenomen migratori ha estat tractat, en detall, en el valuós treball d'Ängela Menages i Joan-Lluís Monjo (2007): Els valencians d'Algèria (1830-1962). Memòria i patrimoni d'una comunitat emigrada. 
[I7] [Com es diu edifici en català?]

- ¿Cómo se dice edificio en catalán?

-Edifici...

-Ya lo sé que e[s] difíci[l], pero de alguna manera se tie[n]e que [d]ecir, ¿no? ${ }^{21}$

[I8] El de «S’il vous plait»

— [...] No te preocupes que venint en mi estàs salvat.

I arriben a Frància. I anaven a agarrar un autobús, es posen allí a la cola, i diu el xòfer; diu:

—Avancez, s'il vous plaît! Avancez, s'il vous plaît! —volia dir que adelantaren.

I ell li diu a l'amic: —Què diu? Què diu?

Diu: -Que diu que mos esperem a l'atre, que este està ple (MenagesMonjo 2007: I88).

[I9] El de «C'est la vie!»

Anava una francesa pel carrer i anava gent, passant gent per ací i per allà, i anaven espanyols també (se n'ixien de l'autobús i del metro que hi havia). Va caure i la falda li'n va anar pac amunt; diu: -Ai!, C'est la vie! C'est la vie! —que volia dir la dona «que és la vida, que havia caigut».

Diu: -Ai, en el meu poble no es diu c'est la vie, allí es diu la poma (Menages-Monjo 2007: I88).

b) La manera de parlar d'una comunitat lingüística és ridiculitzada amb el sentit peculiar o el possible valor onomatopeic d'algunes de les seues expressions:

[20] [Els catalans parlen com borregos]

-Xe! M'han dit que els catalans parleu com borregos.

-Béééééé... Tonteries! ${ }^{22}$

[2I] [Els catalans parlen com granotes]

-Xe! M'han dit que els catalans parleu com les granotes.

- No crec, no crec...23

[22] [Fer-ho com els pollastres]

-Tu saps com ho fan [l'acte sexual] els pollastres?

2I. Acudit escoltat per l'autor a Altea (la Marina Baixa).

22. Acudit escoltat per l'autor a Altea (la Marina Baixa).

23. Acudit escoltat per l'autor a Altea (la Marina Baixa). 
$-[\ldots]$

—Poc a poc; poc a poc [imitant el so del cloqueig dels pollastres]. ${ }^{24}$

c) Per ingenuïtat o per interés, un personatge tradueix d'una llengua a una altra traint el text original de manera més o menys conscient i descarada. Aquesta falsa traducció crea una situació còmica.

[23] El de l'escopetú

$[\ldots]$

—Xe, xe, xe!, mira que escopeta! —diu—; anem a comprar-la!

I diu: -Xe!, com li diríem si la vol vendre?

Diu: -Jo li ho diré! Moixú!, vol vendre l'escopetú?

I el tio diu: $-A h$, je comprends pas!

Diu: -Què ha dit?

Diu: -Que no vol ven-la, que és de son pare. [Aclareix un dels entrevistadors: «Que és del seu papà»] (Menages-Monjo 2007: I86-I87).

[24] [«Beba, beba, que el agua está fresquita y rica»]

—Ei, senyor! No bega vosté de la font, que l'aigua està enverinada i pot morir-se!

- ¡Oiga! ¡No ladre y hábleme en cristiano!

-Usted disculpe. Nada... Que le decía que beba: beba usted a gusto, que el agua está fresquita y rica... ${ }^{25}$

[25] [El de l'escopetú II]

-Eh, moixcú!, vous... Vosté no vol vandrú l'escopetú?

-I l'altre li contesta: «Mira, tonto d'espanyol, vés a Espanya! Qué véns a marejar-mos aquí? Vés-te'n d'ací - l'altre li diu açò en francés.

-I l'altre amic: —Què diu? Què diu?

—Diu que és de son pare, que no vol vendre-la.

I no havia comprés res (Menages-Monjo 2007: I87).

24. Acudit escoltat per l'autor a Altea (la Marina Baixa). Cal observar que aquests tipus de relats humorístics tenen relació amb l'ATUi322A, Grunting Pig. Es tracta, en tots els casos, d'una tosca banalització de l'idioma com a font de l'humor: en el moment que les paraules sonen com les onomatopeies dels cants i els grunys animals, l'idioma queda ridiculitzat i s'hi evidencia la insuficiència del llenguatge humà -fatalitat que, com hem vist, tendeix a sublimar-se amb una o una altra forma del riure.

25. Escoltat per l'autor a Altea (la Marina Baixa). Una versió d'aquest acudit es pot documentar, per exemple, en <http://www.normalitzacio.cat/testimonis/index. php?sec=testimonis\&n=4684> (data de consulta: gener de 20I3): «un pagès avisa un home que l'aigua d'una font és enverinada, i quan aquest li exigeix de males maneres que "le hable en cristiano", es limita a dir-li: "Adelante, beba, beba"». 
d) En un context de diglòssia, membres de la comunitat lingüística minoritzada elegeixen un representant per a comunicar-se amb una autoritat (el rei, el governador, un capità, etc.), a la qual s'ha d'adreçar en la llengua dominant. Aquest portaveu, que òbviament no domina bé la llengua en qüestió, protagonitza un acte de comunicació amb formes macarròniques i divertides incomprensions:

[26] Conte del mallorquí

[...] Doncs diuen que a Mallorca tota la gent anava molt descontenta perquè necessitaven moltes coses i no els en donaven cap, ni una. Per això acordaren d'enviar a Madrid un missatger que exposara davant el rei i les autoritats totes les peticions dels mallorquins. Llavors calia elegir la persona que havia de complir aquesta delicada missió i, com que ningú no volia anar-hi, tragueren sorts i vingué a caure sobre un home de tants, una persona senzilla i que, cosa ben lògica, no sabia parlar castellà. Aleshores els organitzadors de tot aquell assumpte van agafar el nostre home i el van ficar dins una gerra considerant que, si no sentia xerrar mallorquí, ben aviat aprendria a expressar-se en la llengua dels castellans [...].

Llavors comparegué davant del rei i, en l'única llengua que ell coneixia, començà a parlar, i vinga de parlar per tal d'exposar-li les peticions del seus paisans; i tan bon punt va acabar, li presentà la cistella de figues pansides. Però el rei, que havia escoltat bocabadat aquella singular ambaixada, no tenia el costum de calfar-se el cap i, com que no havia entés ni mitja paraula i, encara més, indignat pel present que el nostre home li portava, va manar que el tragueren al pati i que li tiraren totes aquells figues pansides a la cara fins que no en quedara ni una.

Quan es va acabar tot, el pobre mallorquí se'n va tornar a Mallorca. I allí tothom l'esperava amb candeletes i, en ser que va arribar, li demanaren:

—Què? Com ha anat tot? Quin bon acolliment t'ha fet el rei?

El missatger se'ls va mirar de dalt a baix i digué:

- Parlar amb so rei no és parlar amb sa gerra: si en comptes de ser figs són pinys, es barram va en terra (Gonzàlez i Caturla 2005: I27-I29). ${ }^{26}$

\section{[27] [A l'Estall parlen castellà]}

Havia d'anar un home castellà a l'Estall i tots estaven amoïnats, perquè no en sabien, de parlar el castellà. I tots diven:

-Pos, com ho farem pa que mos entenga aquell home que vindrà? Pobres de naltros, no l'entendrem. No sabrem lo que dirà.

I va dir la mossa:

-No patigueu. Jo ja en sé, de parlar el castellà. Perqué vai ser un mes a Saragossa i allí en vai aprendre una mica [...].

26. Aquest relat de Gonzàlez i Caturla ha estat catalogat com a I689 en el RondCat, atenent el motiu de les figues i les pinyes. Tanmateix, Oriol i Pujol (2003: 333) no deixen d'anotar que Neugaard (I995) ja l'havia catalogat com a I322. 
I quan va arribar este home castellà, se va trobar, a casa no estava mes que la mossa, i va dir:

—Buenos días, buenos días, —dice - soy un forastero que viene aquí a vivir. ¿Que no hay nadie aquí en la casa? ¿No está l'ama?

-Diu: - Ha anat a l'hurt a buscá coles pa los purcos — la mossa.

—Bueno - aquell home va dir. Es donava per entés.

Conque a la nit, quan van arribar tots, pués el van convidar a sopar i mentres sopava, pués, l'home anava parlant. I no dia res ningú. Ningú no obria la boca. Com que no sabien parlar el castellà. I aquell home pensava:

_Esta gente, ¿serán todos imbéciles? Que no diuen res. Estan tots callats.

I va la mossa, que era l'única que li parlava i:

- Au, coma, coma señorito, hasta que esté ben farto.

I quina manera de parlar! I vinga parlar, l'home, i no li dava resposta ningú. Conque en acabar de sopar li va dir la mossa, diu:

-Señorito, el llito ya lo tiene feito. Y si quiere pixotear, a devall del llito tiene un pixotiro (Quintana I997: 20I).

[28] [L'explicació al governador]

—Digues; pa això seria menester que algú sabera bé parlar en castellá y en molta política li ú esplicara.

- Si ya está tot anat. Eixe que tú dius ya está buscat.

- ¿Qui es?

-Yo.

_ ¡Ja! ¡Ja! ¡Ja!. Mas fet riure. Si tú no saps una palota de lo que es castellá.

- ¿Que no? Veches, hara vorás tú. Fete conte que estic davant del governaor, en la gorra llevá y en disposisió de dirichirle les queixes que se li han de dirichir en nom de la comisió de fills de Alacant:

«Siñor governaor osia: aspera este hico de esta hidalga terra, en nombre de los presentes, que en vista de que el monesipio en pes, consiente que todos lo re-veneores de la plasa vieja (no li diré de la nova perque per allí no hay mes que soletat) hasen lo que volen y estos siñores consecales elegíos por el naufragio alectoral lo consentixen, farts ya de vore com á conte de carne mos dan pellerancas, greix y hueso [...]» (El Cullerot Alicantí núm. Io6 [3.IO.I886]: I).

e) En relació amb el tipus anterior, també resulta fàcil documentar que un personatge expressant-se amb un «parlar macarrònic» (sense, necessàriament, el motiu de l'elecció d'un representant perquè parle amb l'autoritat) és, en si mateix, l'element central de no pocs relats i formes de l'humor. ${ }^{27}$

27. La premsa satírica valenciana de finals del segle XIX i inicis del Xx recrea adesiara el motiu del personatge catalanoparlant que, en intentar expressar-se en castellà (o en anglés, o en francés, o en italià), ho fa macarrònicament. 


\section{[29] [Canutis, caracolis i xoliverdi]}

-Pos si me dona rabia el vore que tots se la tiren de italians. Cóm voldrás tú creure que á la señoreta de enfront de casa, li preguntava el atre dia la criá:

—Señoreta, qué porte de la plasa? —y la señoreta li dia: —Dos kilos de canutis, cuatre dotsenes de caracolis, carn, sebes tendres, criailles novellis y un chavo de choliverdi.

-Y per aixó se enfada vosté? Home, pot ser que la señora fora neta de algún italiá, y se enrecordara de algunes coses del seu agüelo.

—Qué ha de ser neta de italiá, si el agüelo de ella es el tio Barres Agres el de la Olleria.

-Vol que li diga, que viva la llibertat, y cada ú que parle com li done la gana (El Cullerot Alicantí núm. 29 [I3.4.I885]: I).

\section{[30] [Las tripas a la gola]}

sapies que si el siñor governaor don Cosé Ruis Corbalan, me crida i me diu per qué he dit aixió, yo me estiraré el chaleco, en tocaré la corbata á vore si tinc el floc en mich, en refilaré el bigot, en cuadraré davant dell y despues de escombrar per si tinc alguna cosa en la gola, li diré: «Siñor Governaor, siepa musia, que yo soy un veíno honrao, que no me gustan los actos que estén en contra de la moral y desensia; que las mas de la noches presensio siertas comedias en siertas calles y en siertas casas y en siertas quentes, que me hasen poner las tripas á la gola» (El Cullerot Alicantí núm. 4 [I9.IO.I884]: I).

f) Un relat humorístic, amb sentit etiològic, explica l'origen d'un parlar barrejat, de frontera. ${ }^{28}$

[3I] Com parlen a Guardamar?

[...] Diuen que fa molts anys, quan es va crear el món, el Nostre Senyor anava per les nostres terres repartint les llengües. Havia recorregut tot el Vinalopó distribuint les maneres de parlar i allà on arribava explicava:

28. Oriol i Pujol estableixen, precisament, el tipus català C-O27, «Per què la llengua d'un poble és barrejada», per a l'agrupament dels relats que comparteixen el resum argumental següent: «Nostre Senyor va pel món repartint les llengües. Quan arriba a un poble, li fa peresa continuar o ja no li queden llengües per repartir i diu als seus habitants que parlin com vulguin» (vegeu-ne el resultat de la cerca en <http://www.sre.urv.cat/rondcat/cercar. php?lang=cat\&func=cercar\# $>$; data de consulta: gener de 20I3). Fet i fet, la mateixa Carme Oriol ja observava oportunament, en un article sobre «El contacte de llengües en la narrativa folklòrica»: «Tot i que el catàleg Aarne-Thompson inclou, com hem vist, tipus rondallístics que fan referència als fenòmens de contacte de llengües [com ara els tipus I697 i I699, que l'autora hi comenta i documenta], hi ha altres relats sobre aquesta temàtica que no apareixen referenciats en el catàleg internacional. Un d'aquests relats és una tradició explicativa que apareix documentada en alguns repertoris rondallístics del País Valencià i de la Franja d'Aragó i que podem denominar amb el títol genèric "Parleu com vulgueu"»(Oriol 2003: I28-I29). 
— Vosaltres parlareu valencià — diuen que va dir quan arribà a Elx [...] . — Vosaltres parlareu castellà — va dir quan s'endinsà per l'horta d'Oriola. I amb aquestes paraules repartia a tort i dret les llengües per les nostres comarques [...]. I quan ja se'n tornava cap a Guardamar, ja era un poc tard i el Nostre Senyor es trobava molt cansat [...]. Llavors els de Guardamar el van veure i, com que estaven esperant-lo, quan s'adonaren que no venia, li cridaren:

—Senyor, i nosaltres? Quina llengua hem de parlar?

El Nostre Senyor, que en aquell moment no tenia ganes de calfar-se el cap de tan cruixit com estava, els va dir:

-Ai, fills meus, vosaltres parleu com sapieu.

I per això els de Guardamar, quan parlen, barregen molt el castellà i el valencià (Gonzàlez i Caturla 2005: I3I-I32).

\section{[32] [Com parlen a Guardamar II]}

Una altra versió de la mateixa història, arreplegada a Guardamar, diu que el Nostre Senyor portava les llengües dins un cabàs i que quan va arribar al riu, venia des de Santa Pola, el pont estava romput i no va poder passar a l'altra vora, és a dir, a Guardamar. Llavors va ser quan abocà el cabàs i els va dir allò: «Apanyeu-vos com pugueu» (Gonzàlez i Caturla 2005: I32). ${ }^{29}$

g) Un personatge que viatja i intenta parlar, irrisòriament, l'idioma del país on arriba és comprés perquè casualment l'interlocutor resulta ser compatriota i també domina, per això, la llengua nadiua del protagonista:

[33] El del camareré

[...] Diu: - Â voràs, Rosa, tu no patixques. Ara cride el camareré —i el fa vindre.-Ei, camarere!

Diu: -Sí?

Diu: -Porte'm un pané, un viné i un xocolaté.

I aquell se'n va i li porta el pané, el viné i el xocolaté.

-Tu has vist?

Diu: -Calla, tros de burro!, que si no fóra de Polop t'hagueres mort de fam (Menages-Monjo 2007: I87-I88).

29. Aquesta segona versió és apuntada per Joaquim Gonzàlez i Caturla en una nota a peu de pàgina, just al final de la versió anterior. Rafael Beltran posa en relació aquest relat amb el tipus ATU I699 quan redacta els «Comentaris» de «Joanet, el dels pinyols» (Beltran 2007: 709). L'analogia, en qualsevol cas, sembla evident en relació amb relats com «Així anraonem», documentat per Carlos González Sanz (I996: I82-I83), «Quan va passar Nostro Senyor», també de Carlos González (I996: I82); «Parleu com vulgueu», d'Artur Quintana (IO versions) (I997: 197-I99) o «La vella de Maella que els ensenyava a parlar», de Pasqual Vidal (2005: I2I). 
[34] [Què fem els dos parlant en anglés?]

Un valencià de la Vila Joiosa, quan arriba a Londres, puja a un taxi. Temerós que els anglesos no l'entenguen, fa cas del consell que li han donat, de parlar lentament, amb veu alta i vehement. I demana cridant al xofer: -Peeer faaaavooor! Eeem pooortaaa aaa l'eeestaaació Viiictòòòriiiaaa? I el xofer li contesta, parlant de la mateixa manera:

-Claaar queee sííi! Deee seeeguiiidaaaa!

Content per l'habilitat de fer-se entendre en anglés amb el taxista, decideix encetar amb ell una conversa.

—Iii vooostééé, de quiiinaaa paaart d'Anglaaateeerraaa ééés?

—Nooo! Jooo sóóóc de Reeelleeeuuu!

-Iii siii vooostééé ééés deee Reeelleeeuuu, iii jooo sóóóc dee laaa Viiilaaa, quèèè cooollooons feeem eeels dooos paaarlaaant eeen aaanglééés?30

\section{[35] [El viatge a França]}

Es varen casar dos nóvios i se'n varen anar a Frància... i li va dir el nóvio a la nóvia:

- Mone a la luna de miel a Frància.

—Ai! No saben parlar francés. Es burlaran de mosatros — diu la nóvia.

I el nóvio: - Tu no patisques, jo ja m’ho apanyaré. Mone a Frància.

Se'n van pac a Frància. Quant arriben allí, diu:

-Una paellé d'arrocé, una ensaladé de tomaqué i litro de viné.

I aquell pos, hale!, els va servir. Al sandemà:

-Fes-mos una paelleta d'arrocé, fes-mos un putxeré.

I quan se'n varen vindre, que varen pagar el compte i això, li diu l'home a la dona:

—Tu veus com hem quedat bé?

I el camarero li va dir:

-Imbècil de collons! La sort que tens tu és que sóc de Tollos, si nos t'haveres mort de fam ací (Guardiola-Beltran 2005: 229-230).

30. Acudit escoltat per l'autor a Altea (la Marina Baixa). 
h) Entre dos parlants de distints dialectes d'un mateix idioma es produeix un malentés com a conseqüència d'una especificitat dialectal que l'altre parlant desconeix. La situació còmica que se'n genera serveix per a ridiculitzar la diferència lingüística que dóna peu a la confusió: ${ }^{31}$

[36] [La banda, la lleves]

Conten que una volta estaven organitzant una gran manifestació a València. L'agent coordinador d'aquella mobilització parlava telefònicament amb un amic de Monòver, que s'encarregava de gestionar quines entitats monoveres acudirien a l'acció reivindicativa de la capital. El delegat de Monòver dubtava si hi podia portar o no la banda de música, perquè comportava un cost important:

—Què faig de la banda de música?

El coordinador de l'esdeveniment, molt preocupat perquè no tenia prou recursos econòmics, va contestar de seguida, provant de reduir despeses:

—No, no... La banda, la lleves!

I aquell de Monòver, efectivament, «la va lleva[r]». Quan el de València va veure tots els músics abaixant dels autobusos li va cridar:

-Però no t'havia dit que llevares la banda?

-Pos això he fet: l'he llevat...32

\section{[37] [Que s'ofegue!]}

Un home de Castelló passejava pel port de València. Una jove que passava a prop va entropessar i va caure a l'aigua. L'home, per avisar i demanar auxili, va començar a cridar:

—Que s'ofegue, que s'ofegue!

I li van pegar una pallissa.

\section{[38] Contalla del garbell de Maella}

A Maella a l'aina que s'empleave per a la neteja i porga del blat de trilla se li deie garbell, a diferència de la resta de les viles comarcanes que tenie el nom d'arer $[\ldots]$.

3I. Normalment, es tracta de varietats dialectals diatòpiques, o dialectes geogràfics (com en el cas del relat [2], «Lo pont del mesquí»); però l'efecte humorístic també es pot produir per raó de diferències dialectals diastràtiques o socials. El parlar caló, per exemple, fa possible el joc de paraules que convoca l'humor en un acudit com aquest: «Perquè [sic] un gitano es vol posar "Gitaner" al Peugeot 205 tunejat? Hombre! [sic] Perquè nosaltres ens hi posem "Pioner"!!» (documentat en <http://www.fotolog.com/iele/I6347755/>; data de consulta: gener de 20I3).

32. Contalla escoltada per l'autor a Alacant (l'Alacantí). Cal notar que a Monòver, com en molts altres municipis del Vinalopó Mitjà i el Baix Vinalopó, el verb lleva[r] té el sentit de 'portar', mentre que en valencià general té — com en el català estàndard— el valor de 'retirar, separar una cosa d'allò de què és part o membre'. 
Los hòmens de l'era s'havien oblidat de pujar l'arer del blat — garbell—a Maella i li van manar a la mossa que l'anare a buscar, dient:

-Vés a puiar lo garbell que mo l'ham dixat.

La mossa de Massalió desconeixia eixa paraula maellana i se va entendre que li van dir 'lo gat vell' en compte de 'garbell'. Per més que la mossa va buscar per tota la casa no va haver manera de trobâ'l. Eixe gat tenie una menuda cria, o sigue, un gatet carbassenc. Ni curta ni pereüda, la mossa va agarrar lo gatet i se'n va anar cap a l'era. Quan los hòmens de l'era la van veure vindre li van dir:

—Qué portes astí? T’ham dit que dugueres lo garbell!

I la mossa los va contestar tota enfadada:

-Cony, no l'hai trobat lo gat vell i he pensat que ere igual dur lo jove (Quintana I995: I98-I99).

i) En un determinat context comunicatiu, un personatge fa servir una expressió pròpia d'un registre que - per massa formal o per ser argot- no resulta accessible a l'interlocutor: el fet provoca una confusió lingüística que acaba derivant en una situació còmica.

[39] Beniardà

[...] - Tant de poder tenia el personatge [l'últim senyor de Guadalest]?

-Manava de tot i de tots. De les terres i de les collites, dels homes i de les dones. A les dones, quan eren en temps de cria, els demanava que li deixassen mamar. I pobreta la que s'hi negués!

-Potser era caquèctic i la lactació era una cosa vital per a la seua persona.

- Jo això que acaba de dir no sé què és, però el tipus aquell era un mamó (Capó I980: I29).

\section{[40] [Una copulació i l'això del coit]}

Una dona jove i atractiva va al metge acompanyada pel seu home. Després de l'exploració de rigor, el metge recomana a l'home:

- Mire. La seua dona es troba una mica deprimida, insatisfeta i necessitada de... Vull dir: fóra bo que practicaren una copulació. Ja m'entén: que li realitze el coit.

L'home, per ignorància — i per vergonya de no preguntar què significava això de «practicar una copulació» $\mathrm{i}$ «realitzar el coit»—, li demana:

-Doctor, per favor: i ara que estem ací, no li ho podria fer vosté mateix, tot això, que segur que ho sap fer millor que no jo?

-Però bon home!

- Per favor, per favor. Li ho agrairia moltíssim!

-Però... Està segur? La seua dona voldrà?

—Sí, sí, sí. Jo li ho faré entendre. 
I adreçant-se a la dona:

-Entra, que el doctor et practicarà una copulació i et realitzarà el coit. Crec que és lo millor. I jo estic d'acord.

Quan la dona torna a entrar a la consulta, se sent un escàndol de gemecs que evidencien el plaer sexual. I l'home, que espera fora, primer es mostra nerviós, però de seguida somriu beatíficament i diu al pacient del costat: -Sort que sé que el doctor està practicant una copulació i realitzant l'això del coit, que si no diria que el cabró s'està xapant la meua dona!33

j) Les diferents paraules que integren una expressió signifiquen una cosa diferent si són pronunciades juntes, en una única paraula més llarga, que sona igual que la suma de les paraules curtes de l'expressió. La confusió entre una forma (la de la paraula llarga) i l'altra (la de les dues o més paraules curtes) dóna lloc al malentés i el corresponent efecte irrisori. ${ }^{34}$

[4I] Gallegos

—Cariño, me abrumas.

- Tu también me abrumas cariño.

—No no, que si me abru más!35

[42] [Davall del llit té la mà]

-Por hacer el pardillo yo tambien doy un codigo al primero que me diga «debajo de la cama tiene la mano Maria» en catalán

—iiiSota el llit te la ma-Maria!!! ajajajajajajaja. ${ }^{36}$

[43] [Fi deu!]

$\mathrm{P}[\mathrm{er}]$ a escarnir els xiquets menuts que, com jo, érem molt flacs — prims com fideus- mos fe[i]en este joc:

-Viga, com[p]ta: fi uno, fi dos, fi tres, fi quatre...

I tu continuaves:

33. Acudit escoltat per l'autor a Altea (la Marina Baixa).

34. A aquest tipus d'efecte humorístic correspondrien els relats [I2], [I3] i [I4]; i també el [7] i el [8] (on a l'homofonia per fonètica sintàctica s'afig la confusió entre parlants de llengües diferents).

35. Acudit explicat a l'autor per Manuel Huertas Rodríguez, de Los Montesinos (el Baix Segura), l'any I989. Documentable, per exemple, en el fòrum electrònic <http://www.forocoches.com/foro/show thread.php?t=2326535> [data de consulta: gener de 20I3].

36. Acudit conegut des de fa dècades per l'autor. Documentat ací en el fòrum electrònic $<$ http://zonaforo.meristation.com/foros/viewtopic.php?p=I6350832> [data de consulta: gener de 20I3]. 
—Fi cinc, fi sis, fi set, fi huit, fi nou i fi deu!

—Fi deu! Fideu! Has dit fideu! Eres un fideu! ${ }^{37}$

[44] [Maca... gat!]

-Vinga, un joc... Jo dic una paraula i tu l'has de repetir, però dient davant «maca». Per exemple: si jo dic «taula», tu has de dir «maca taula». Si dic «cadira», tu «maca cadira», d'acord?

$-[\ldots]$

— «asa!»

— «Maca casa!»

— «almera!»

— Maca palmera!»

— Tossal!»

— «Maca tossal!»

— «Gos!»

— Maca gos!»

— «at!»

—«Maca gat!»

—Ha, ha, ha... Mira! Mira! S'ha cagat, s'ha cagat! El xiquet diu que s'ha cagat! $3^{8}$

k) El desconeixement d'un idioma estranger comporta, per incomprensió d'una informació rellevant, una fatal conseqüència per a algú. Aquest, tanmateix, amb la innocència pròpia de la ignorància, reacciona amb un comentari o una acció ingènua que, per contrast amb les conseqüències de la incomprensió, té un efecte còmic:

[45] \# El del «Ocho»

Diu que un del poble se'n va anar a la mili fa molts anys. El Capità els va posar un dia a tots en filera i va dir que el que tinguera el número que ell trauria, hauria de netejar els serveis. Va traure el número [vuit] i no parava de cridar, com que ningú li contestava cada vegada s'enfadava més i li afegia més faenes. Finalment, en veure el capità tan enfurit, el del meu poble digué: pobre del qui tinga el «ocho», gràcies que jo tinc el vuit! 39

37. Escoltat a Nicolau Borja Pérez, pare de l'autor, a Altea (la Marina Baixa).

38. Joc lingüístic documentat a Altea: escoltat per l'autor a Angelita Polvoreda, Angelita la Galla, al novembre de 201 .

39. Es tracta d'un acudit arxiconegut, des de fa dècades, al País Valencià. El text citat ha estat documentat en el fòrum digital <http://www.vilaweb.cat/www/capde7mana/ forum $\mathrm{id}=539938 \&$ pagina $=5>$ [data de consulta: gener de 2013] . 


\section{Conclusions}

Així, doncs, si bé es mira, al darrere d'una rialla o d'un somriure hi ha sempre una tragèdia. Fet i fet, l'humor pren base en el fracàs de la condició humana i constitueix, precisament, una estratègia — privativa de l'espècie - per a la superació o la sublimació de les inclemències vitals. Els acudits que inventem i contem delaten la feblesa de les institucions polítiques i religioses suposadament decoroses, elevades, respectables; evidencien la vulnerabilitat del cos humà; ens en recorden la condició zoològica, biològica i mortal, etc. És en aquest mateix sentit existencial que també les llengües - la comunicació verbal i els seus insuccessos- són una font de calamitats, confusions i rialles: quan el llenguatge trontolla, allà on les paraules fracassen, no solament queda en evidència la presumpta dignitat de l'espècie, sinó també una dramàtica limitació en les formes de la comunicació, i en les possibilitats de concepció del món. En últim terme, el fracàs del llenguatge és el fracàs de l'ànima humana — nua, òrfena, aïllada, terriblement sola davant les complexitats de l'existència.

Tenint en compte aquests fonaments de l'humor sobre malentesos lingüístics, i partir d'un corpus concret de narracions populars que tradicionalment han estat catalogades com a ATU I699 («Malentesos entre parlants de diferents llengües»), les consideracions analítiques d'aquest article han provat de mostrar no solament la contigüitat, a voltes poc definida, de tipus com el I698, I698B, I698D, I698H, I698I, I698J, I698K, I698M, I322, I322A i I700, sinó també algunes dificultats de catalogació per a contarelles de riure que es basen en malentesos no necessàriament de sords (factor comú en la sèrie I689) o entre persones que parlen llengües distintes (atribut distintiu del tipus I699). Tenint-les en compte, i atenent de més a més que les confusions de l'humor verbal són òbviament específiques de cada sistema lingüístic (privatives, per tant, de cada llengua; intraduïbles; sense possibilitat de migració internacional; inevitablement eixorques quant a possibilitat de comparació i catalogació universal; improductives per al mètode historicogeogràfic), les reflexions ací exposades apunten a l'interés de definir, alternativament, tipus de contextos i situacions comunicatives en què es manifesten equívocs i fracassos del llenguatge: formes de la corrupció comprensiva i interactiva capaces de desinflar la suposada suficiència de les paraules i, doncs, de desfermar un efecte còmic.

En aquest sentit, i ni que siga per aportar un punt de partida per a reflexions i sistematitzacions posteriors, hem estimat oportú consignar i exemplificar algunes fórmules recurrents en els relats humorístics d'arrel lingüística: els malentesos per falsos amics, la ridiculització d'una comunitat lingüística a partir d'una determinada peculiaritat idiomàtica; les males traduccions aberrants, ingènues $o$ tendencioses; el motiu del representant d'una comunitat lingüística minoritzada que, en un context de diglòssia, no reïx a expressar-se ortodoxament en la llengua de l'autoritat; les formes divertides d'un parlar macarrònic; els relats etiològics que expliquen l'origen d'un parlar barrejat de frontera; la casual superació d'una dificultat lingüística a l'estranger pel fet que l'interlocutor resulta ser del mateix origen (i la mateixa llengua) que el viatger; els malentesos causats per les especificitats dialectals; els entrebancs comunicatius per raó de registre; els equívocs per l'homofonia que de vegades provoca la fonètica sintàctica; les fatals conseqüències que poden resultar del desconeixement d'una llengua estrangera; etc. 
La consideració d'aquestes casuístiques i d'altres podria — aquest n'era el propòsit- contribuir a facilitar noves opcions de catalogació i una millor comprensió quant a les pautes de la jocositat popular amb base verbal. O no. Perquè l'humor, higiènicament terapèutic i idiosincràticament humà, potser té la seua gràcia i fa el seu efecte balsàmic sense necessitat que ens el prenguem tan seriosament...

\section{Referències bibliogràfiques}

BATAlLER, Josep (I98I): Contalles populars valencianes, I. València: Institució Alfons el Magnànim.

- (I997): Rondalles i acudits valencians. Gandia: CEIC Alfons el Vell.

- (200I): Rondalles de les comarques centrals valencianes. Ontinyent: Caixa d'Estalvis d'Ontinyent.

CAPÓ, Bernat (I980): Espigolant pel rostoll morisc. València: Eliseu Climent.

FreUd, Sigmund (I905): Der Witz und seine Beziehung zum Unbewußten. LeipzigViena: Franz Deuticke [Hi ha traducció al castellà en El chiste y su relación con lo inconsciente. Madrid: Alianza, 20oo. I se'n pot consultar, també, una versió electrònica lliure en <http://es.scribd.com/doc/IO22803/Freud-SigmundChiste-y-su-relacion-con-lo-inconsiente>. La cita i la paginació corresponen a aquesta última versió].

— (I927): «Der humor». Almanach I928: 9-I6 [Se'n pot consultar la traducció a l'anglés en <http://www.scribd.com/doc/345I5345/Sigmund-Freud-Humor-I927>. Data de consulta: gener de 20I3].

FUSTER, Joan (I969): Diari (1952-1960). Barcelona: Edicions 62.

GonzÀlez I CATurla, Joaquim (2005): Rondalles del Baix Vinalopó. Contes populars. Alcoi: Marfil [La primera edició és de I985].

GonzÁlez SANZ, Carlos (I996): Despallerofant. Recopilación y estudio de relatos de tradición oral recogidos en la comarca del Bajo Cinca. Santa Margarida de Montbui: Institut d'Estudis del Baix Cinca/Ajuntament de Fraga.

GUARDIOLA, Maria Isabel; Vicent BELTRAN (2005): Bolulla la caramulla: cultura popular i llengua d'un poble. Alacant: Institut Alacantí de Cultura Juan Gil-Albert.

LIMORTI, Ester; Artur QUINTANA (I998): El Carxe. Recull de literatura popular valenciana de Múrcia. Alacant: Institut de Cultura Juan Gil-Albert.

MENAGES, Àngela-Rosa; Joan-Lluís Monjo (2007): Els valencians d'Algèria (18301962). Memòria i patrimoni d'una comunitat emigrada. Picanya: Edicions del Bullent.

NeugaARD, Edward J. (I995): Anthology of Catalan Folktales. Nova York: Peter Lang.

ORIOL, Carme (2003): «El contacte de llengües en la narrativa folklòrica». Dins Joan ARMANGuÉ (ed.): Le lingue del popolo. Contatto linguistico nella letteratura popolare del Mediterraneo occidentale. Càller/Dolianova: Arxiu de Tradicions/ Grafica del Parteolla, p. I27-I33. 
Els relats humorístics d'arrel lingüística: consideracions a propòsit...

ORIOL, Carme; Josep M. PujOL (2003): Índex tipològic de la rondalla catalana. Barcelona: Departament de Cultura. Centre de Promoció de la Cultura Popular i Tradicional Catalana.

- (2008): Index of Catalan Folktales. Folklore Fellows' Communications 294. Hèlsinki: Suomalainen Tiedeakatemia.

PeredA, Alberto (I983): «El chiste». Temas de Psicoanálisis núm. 2 (I983): I9-2O.

QUINTANA, Artur (I995): Lo Molinar: Literatura popular catalana del Matarranya $i$ Mequinensa. Calaceit: Instituto de Estudios Turolenses/Associació Cultural del Matarranya/Carrutxa.

- (I997): Bllat colrat! Literatura popular catalana del Baix Cinca, la Llitera i la Ribagorça. Calaceit: Instituto de Estudios Altoaragoneses/Institut d'Estudis del Baix Cinca/Institut d'Estudis Ilerdencs/Diputació General d'Aragó.

RondCat: cercador de la rondalla catalana. Arxiu de Folklore. Departament de Filologia Catalana de la Universitat Rovira i Virgili, <http://www.sre.urv.cat/ rondcat> [data de consulta: gener de 20I3].

UTHER, Hans-Jörg (2004): The Types of International Folktales. A Classification and Bibliography. 3 vols. Folklore Fellows' Communications 284-285-286. Hèlsinki: Suomalainen Tiedeakatemia.

VIDAL, Pasqual (2005): A la falda de la iaia. Literatura oral de Massalió. Calaceit: Associació Cultural del Matarranya. 